\title{
Dominance and Influence of Social Context on Foraging by Eurasian Siskin (Carduelis spinus)
}

\author{
Nehafta Bibi', Muhammad Shafiq ${ }^{2}$, Munawar Saleem Ahmad ${ }^{3}$ and Haitao Wang ${ }^{1,4, *}$ \\ ${ }^{1}$ Jilin Engineering Laboratory for Avian Ecology and Conservation Genetics, \\ Northeast Normal University, Changchun 130024, China \\ ${ }^{2}$ Institute of Numerical Sciences, Kohat University of Science and Technology, \\ Kohat 2600, Khyber Pakhtunkhwa, Pakistan \\ ${ }^{3}$ Department of Zoology, University of Swabi, Swabi 22621, Khyber Pakhtunkhwa, \\ Pakistan \\ ${ }^{4}$ Jilin Key Laboratory of Animal Resource Conservation and Utilization, Northeast \\ Normal University, 5268 Renmin Street, Changchun 130024, China
}

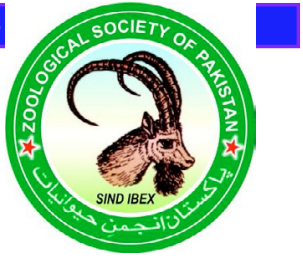

CrossMark

\begin{abstract}
A B S T RA C T
The tendency to consume greater amount of food in social context has traditionally been attributed as social facilitation, which is an important characteristic of social and flocking birds. In this study, we investigated Eurasian siskin (Carduelis spinus) dominant individuals for neophobia and influence of social context on foraging. In our experiments, a subject (observer) was presented with three novel and familiar food in each of three contexts: asocial, first social context (conspecifics without food) and second social context (conspecifics with food). The results showed that individuals preferred to consume novel food only in social context comparing to asocial. Furthermore, individuals consumed significantly greater amount of familiar food in social context than asocial. Our results showed that dominant male Eurasian siskins may reduce neophobia in social context and increase food intake. Present study showed that flocking in the Eurasian siskin and other gathering birds may influence individual fitness.
\end{abstract}

Article Information
Received 27 April 2017
Revised 20 July 2017
Accepted 02 October 2017
Available online 22 November 2017
Authors' Contribution
NB and HW conceived and designed
the study, collected the data and wrote
the article. MSA helped in writing of
the manuscript. MS helped in data
analysis.
Key words
Social facilitation, Carduelis spinus,
Foraging behavior, Personality,
Neophobia, Dominance.

\section{INTRODUCTION}

$\mathrm{T}$ The tendency to consume greater amount of food in social context has traditionally been attributed as social facilitation (Pliner et al., 2006). Social facilitation is an important characteristic of social and flocking birds, as the behavior of one individual can induce similar behavior in other group members (Palestis and Burger, 1998). Social facilitation can enhance the benefits of flock by contributing to foraging success, reproductive synchrony within flock and anti-predator defense (Clayton, 1978). Consumption of greater amount of food during social context then asocial correlates positively with the number of individuals that are present in social context (Herman et al., 2003). Presence of conspecifics (independent of its behavior) can also produce motivational changes that can either increase or decrease individual performance, depending on whether the change in motivation produce a behavioral change compatible or incompatible with learned or to-be-learned behavior. Social facilitation comprises two main circumstances: effects of coaction and audience

\footnotetext{
Corresponding author: wanght402@nenu.edu.cn 0030-9923/2017/0006-2201 \$9.00/0

Copyright 2017 Zoological Society of Pakistan
}

effect (Zajonc, 1965). Presence of conspecifics or effects of coaction results in maximum utilization of food, but in contrast in case of audience effect individuals usually consume less amount of food (Herman, 2015). Greater consumption of food in the presence of conspecifics was found in several species e.g. blue jays (Cyanocitta cristata), ravens (Corvus corax), marmosets (Callithrix jacchus) (Coppinger, 1969; Heinrich, 1988; Voelkl et al., 2006).

Though actual mechanism and structure underlying socially facilitated feeding is not clearly known and needs further investigation but, according to Fragaszy and Visalberghi (2004) one functional advantage of this phenomenon is might be the increased acceptance of novel food by naïve individuals. Novel food consumption might later result in animals' health risk, and might be the possible reason to explain why individuals of many species are originally reluctant to incorporate novel food in their diet, a tendency described as food neophobia. Food neophobia is known to reduce by presence or interaction of conspecifics (Voelk et al., 2006). However, if socially facilitated foraging functions to promote novel food acceptance, rather than inflating food utilization generally, animals should selectively eat those novel foods they have observed others eating (Visalberghi and Addessi, 2001). 
Animals showing an aversion to novelty are known as neophobia. Individuals of many species differ consistently in their neophobia (Bebus et al., 2016) and their behavioral reactions toward novel and challenging situations, e.g. the great tit (Parus major) (Verbeek et al., 1994), the poecilid (Brachyraphis episcopi) (Brown et al., 2005), and the Sardinian warblers (Sylvia melanocephala momus) (Mettke-Hofmann and Greenberg, 2005; Mettke-Hofmann et al., 2005a). These consistent individual behavioral differences have been termed as personalities (Wilson et al., 1993; Drent et al., 2003). Neophobia is often used as a trait of nonhuman personality, because it is considered as stable response to challenges or risk across novel situations and across time (Dall et al., 2004). This behavioral trait is common to many species e.g. warblers (Dendroica castanea and Dendroica pensylyanica, Greenberg (1990)), and capuchin monkeys (Cebus paella) (Visalberghi and Fragaszy, 1995; Visalberghi et al., 2003a). Neophobia can be affected by early experience, ecology, and social contexts (Addessi et al., 2007).

Previous studies have shown that social and flocking birds spend less time vigilant and more time foraging than alone (review in Krause and Ruxton, 2002; Yang et al., 2015; Wan et al., 2016). However, in four species of goose when flock size increased over considerable range foraging time also increased and vigilant decreased (Drent and Swierstrs, 1977; Inglis and Isaacson, 1978). In social and flocking species, individuals differ in their dominance rank, social bond and kinship with other flock members, all of which can have an important effect on foraging behavior and performance (East and Hofer, 2010; Marshall et al., 2012; Goodale et al., 2015). However, there is a general prediction that greater spatial clumping of resources should lead to a greater influence of social effects on foraging performance due to resources being more monopolized (Yang et al., 2015). For example, Vahl et al. (2005) found that dominant ruddy turnstones (Arenaria interpres) utilized significantly greater amount of food where food resources were spatially clumped. Similarly, in a study of common cranes (Grus grus) dominant individuals only engaged in agonistic interaction in context where their intake fell below a certain threshold (Stillman et al., 2002). Foraging behavior were also studied in two common scorpion species i.e. Hottentotta tumulus (Fabricius 1978) and Odontobuthus odonturus (Pocock 1897) (Ahsan and Tahir, 2016).

The Eurasian siskin (Carduelis spinus), a small monogamous granivorous cardueline finch, has a social system consisting of both transient and resident individuals in a particular habitat (Senar et al., 1992). Transient individuals constitute $92 \%$ of total population making flight of $10-40 \mathrm{~km}$ in a single day and stay in one habitat for short period; in contrast, resident individuals are present in specific area for prolonged period making short flights typically less than $3 \mathrm{~km}$ (Senar et al., 1992; Pascual and Senar, 2014). This difference in movement patterns is not related to sexual or age differences. Due to low mortality rate, it is easy to keep them in captivity (Senar and Camerino, 1998; Senar and Domènech, 2011). Black bib in Eurasian siskin is used to categorize dominance and personality (Senar et al., 1993; Senar and Camerino, 1998). Individuals with large black bib show more exploratory personality and are dominant over females (Mateos-Gonzaléz and Senar, 2012).

Eurasian siskin is also a socially foraging species, therefore in the present study we provided with an opportunity to exploit social information for their foraging behavior (Senar et al., 1992). Our first aim was to examine whether social context can reduce neophobia and facilitate foraging behavior in the Eurasian siskin. Our second aim was to examine whether they may use social information to guide their foraging behavior.

\section{MATERIALS AND METHODS}

\section{Catching and housing}

Eurasian siskins were caught using mist nest from Changchun city and surrounding areas in Jilin Province, China, on January 11-2017. Birds were transported to laboratory within two hours. Upon arrival in research laboratory we kept individuals under $12 \mathrm{~h}: 12 \mathrm{~h}$ daylight regime in cages of $25 \mathrm{~cm} \times 30 \mathrm{~cm} \times 30 \mathrm{~cm}$ with two small perches placed inside. Perilla seeds, pine seeds and commercial canary mixtures were provided as familiar food, and water ad libitum (Senar and Camerino, 1998).

\section{Dominance status}

We used the size of the black bib, which is highly correlated with dominance, as an indication of dominance (Senar et al., 1993). We measured size of black bib (length and width) by tilting birds head back in line with body and the area was calculated following Senar and Camerino (1998). We used only transient male individuals because the usefulness of black bib as signal of dominance is especially relevant to transient (Senar et al., 1992). Based on the area we categorized individuals as large bib and without bib. Four individuals without bib were excluded. Ten individuals with bib size (median bib size was 17 $\mathrm{mm}^{2}$, and $95 \%$ confidence interval (CI) was $13-21 \mathrm{~mm}^{2}$ ) were included in this study. Among our caught birds none of individual had a larger bib size, e.g. bib size $>35 \mathrm{~mm}^{2}$ as in the study of Senar and Camerino (1998).

\section{Experiment setup}

We used two cages adjacent to each other $(0.9 \mathrm{~m} \times$ 
$0.4 \mathrm{~m} \times 0.5 \mathrm{~m})$ in each of three contexts. 1) In asocial context, cage adjacent to focal cage were empty however in other two social contexts a conspecifics were present (Verbeek et al., 1996; Dally et al., 2008). Each context comprises only one test. 2) During the first social context a conspecific were only present but without novel or familiar food. 3) The third context was that second social context where conspecifics were also provided with both familiar and novel food like the focal subject. Each individual was tested both as subject and conspecifics. Sequence to test individual in all three contexts were pseudo randomized to avoid testing the same bird in a single day. We provided $1 \mathrm{~g}$ of total novel and familiar food in each context (we selected this amount because we have first conducted a pilot experiment to know how much amount of food each individual can consume within a period of $3 \mathrm{~min}$. However, data of the pilot experiments were not included in this study). We weighed amount of total novel and familiar food before and after trial. We recorded neophobia and latency to feed for $3 \mathrm{~min}$ (Senar and Camerino, 1998) and then the trial was terminated. Birds that didn't feed novel or familiar food during $3 \mathrm{~min}$ were assigned to the maximum latency of 180s. Each trial was started as soon as the subject (the observer) enters the tested cage where conspecifics were already present in front cage (Addessi and Visalberghi, 2006). A video camera was used to record experimental birds for $3 \mathrm{~min}$. The video tapes were later analyzed for approach latencies (both novel and familiar food). Experimental birds were also observed behind the observation screen (Senar and Camerino, 1998).

\section{Foraging and neophobia test}

\section{Asocial context}

Trial was started in their home cages at 09:00 $\mathrm{h}$ to 13:00 h. Individuals were deprived of food 2 hours before commencement of the trial (Senar and Camerino, 1998; Dally et al., 2008). As the trial started individuals were provided with familiar food (canary mixture) and novel food (chocolate cookies mesh) (Table I).

Table I.- Assignment of familiar and novel food in each context.

\begin{tabular}{llc}
\hline Context & \multicolumn{1}{c}{$\begin{array}{c}\text { Food } \\
\text { (Familiar / Novel) }\end{array}$} & Sex \\
\hline Asocial & $\begin{array}{l}\text { Canary mixture / } \\
\text { Chocolate cookies } \\
\text { Pine seed / Pop corn }\end{array}$ & Male \\
$\begin{array}{l}\text { Social } \\
\text { (Conspecifics without food) }\end{array}$ & Perilla seeds / Bread & Males \\
$\begin{array}{l}\text { Social } \\
\text { (Conspecifics with food) }\end{array}$ & & \\
\hline
\end{tabular}

\section{Social context}

We used popcorn (novel food) and pine seeds (familiar food) during the first social context where conspecifics were only present in front cage but not provided with food. During the second social context we presented bread (novel food) and perilla seeds (familiar food) to the subject and conspecifics were provided with only familiar food (perilla seeds). We meshed novel food to the size of small grains like perilla seeds so individuals can eat (Addessi and Visalberghi, 2006).

\section{Statistical analysis}

As our data violated normality assumptions, we used non-parametric tests. We carried out Friedman analysis of variance (ANOVA) to compare latency to approach novel and familiar food and the total amount of novel and familiar food consumed across contexts, and Wilcoxon signed rank test between contexts. We set 0.05 as alpha and presented original $\mathrm{p}$ values (Addessi and Visalberghi, 2006; Dally et al., 2008). Data were analyzed using SPSS (V. 22).

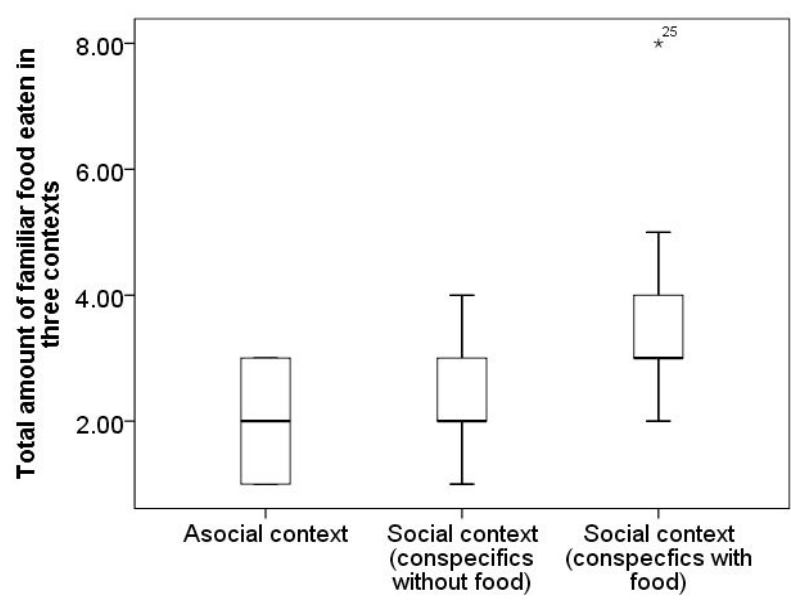

Fig. 1. A box and whisker plot of the median and inter quartile range (IQRs) of total amount of familiar food.

\section{RESULTS}

The Eurasian siskin preferred and consumed significantly greater amount of familiar food than novel food in all three contexts; asocial context $(\mathrm{N}=10, \mathrm{Z}=$ -2.836, p <0.05), social context (conspecifics without novel or familiar food) $(\mathrm{N}=10, \mathrm{Z}=-2.844, \mathrm{p}<0.04)$ and social context (conspecifics with familiar food) $(\mathrm{N}=10$, $\mathrm{Z}=-2.814, \mathrm{p}<0.05$, Figs. 1 and 2 ). Novel food was not eaten in asocial context (Fig. 2). Total amount of food eaten in asocial context was lower than social context (novel food, Freidman's ANOVA, $\chi 2=6.000, \mathrm{~N}=10, \mathrm{p}$ 
$=0.050$, familiar food, Friedman's ANOVA, $\chi 2=7.357, \mathrm{~N}$ $=10, \mathrm{p}=0.025)$. Latency to approach familiar food was greater in asocial context than social context (Friedman's ANOVA, $\chi^{2}=9.053, \mathrm{~N}=10, \mathrm{p}=0.011$, Fig. 3 ). Individuals didn't approached novel food in asocial context but they significantly approach novel food in social context (Friedman's ANOVA, $\chi^{2}=7.946, \mathrm{~N}=10, \mathrm{p}=0.019$, Fig. 4).

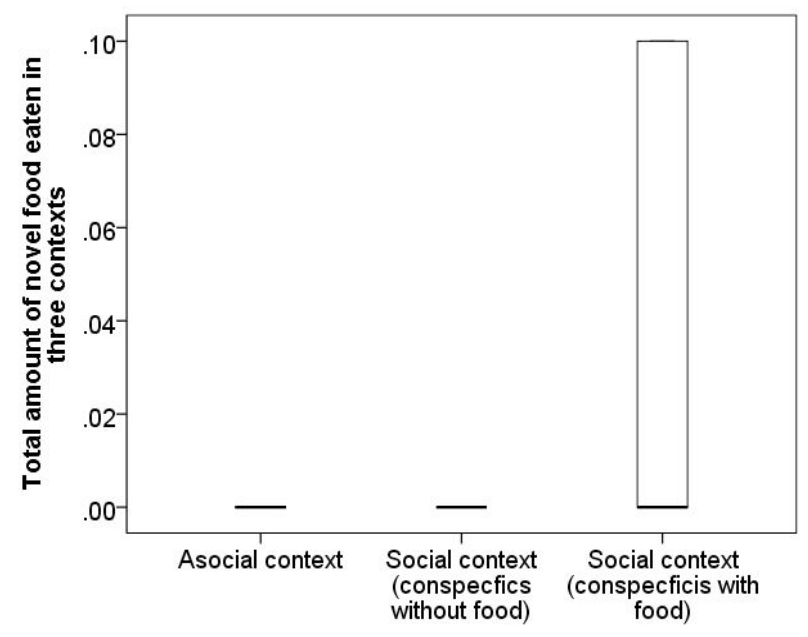

Fig. 2. A box and whisker plot of the median and inter quartile range (IQRs) of total amount of novel food eaten.

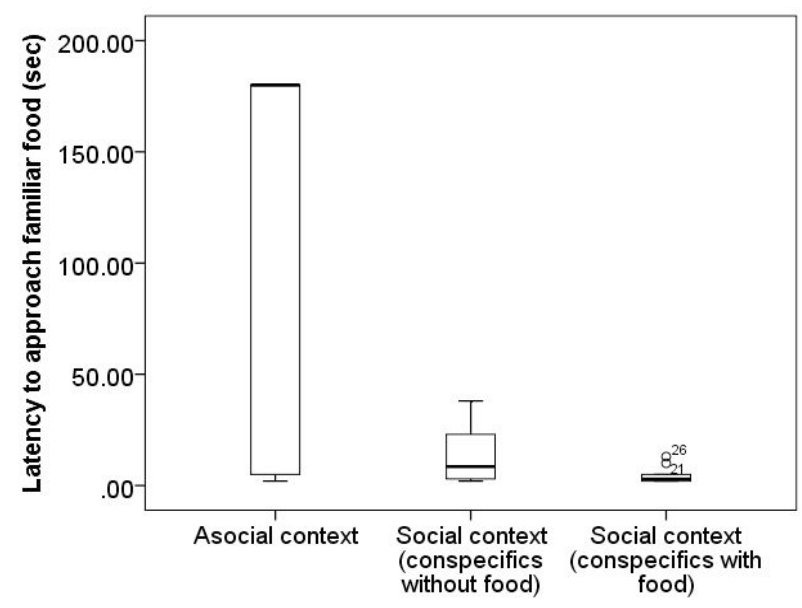

Fig. 3. A box and whisker plot of the median and inter quartile range (IQRs) of approach latency to familiar food.

\section{DISCUSSION}

In the present study, we showed that Eurasian siskin individuals ate significantly greater amount of familiar food than novel food in all contexts. This suggested a significant variation in food preference and utilization across contexts. One reason for increased food consumption in social species might be reduced the need for each individual to engage in vigilant behavior like scanning for potential predators (Caraco et al., 1980; Lima and Bednekoff, 1999). When animals are exposed to predation risk, they might benefit from exploiting socially available information as to food deliciousness rather than assessing that similar food resource (Laland, 2004). Another possible reason for greater consumption of food and reduction of neophobia is interspecific competition because birds living in groups experience possibly greater interspecific competition than alone. Therefore, group-living species may be less neophobic and/or more explorative (Greenberg and Mettke-Hofmann, 2001). Our study was also comparable to Pulliam and Caraco (1984) where they showed that in winter flocking birds, intake rate of group foragers is higher than that of solitary individual, e.g. one of the main advantage of aggregation in foraging birds is a reduction in predation risk (Giraldeau, 2008). But according to Sansom et al. (2008) an increase in group size may also result in an increase in interference competition among group members, which may reduce food intake rate (Beauchamp, 1998) and increase the time spent in vigilance (Knight and Knight, 1986).

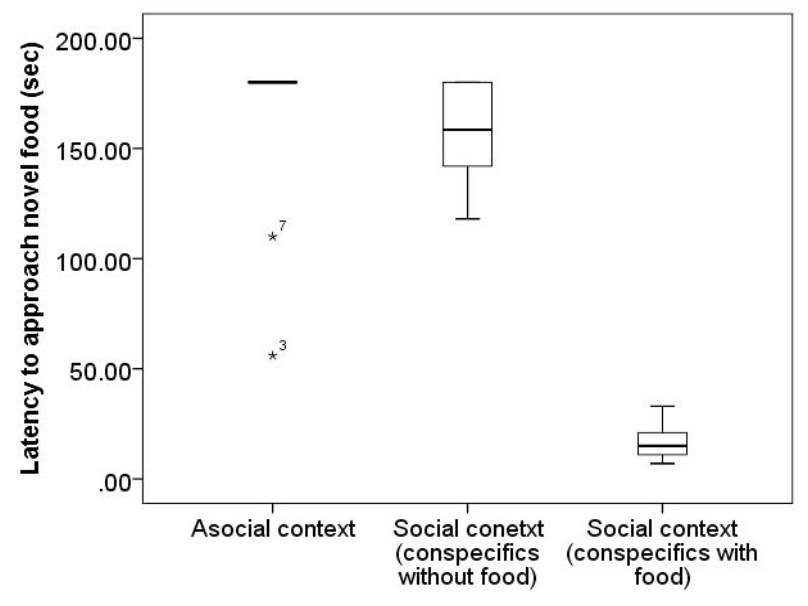

Fig. 4. A box and whisker plot of the median and inter quartile range (IQRs) of approach latency to novel food.

When animals show an aversion to unknown risk, they express a behavior, known as neophobia (Greenberg and Mettke-Hofmann, 2001). Neophobia may provide an advantage to animals by reducing their exposure to unknown danger but can also impose costs by preventing the exploration of potential resources (Greggor et al., 2015). These costs and benefits of risk taking are likely to differ over contexts and time in a way that could alter the expression of neophobia. For instance, it could be advantageous to adjust neophobia levels when dangers or 
environmental opportunities changed, such as predation pressure or food availability (Brown et al., 2013). Food neophobia is influenced by factors like, the type of food (Visalberghi and Fragaszy, 1995; Visalberghi et al., 2002), and the number of exposures to a novel food etc. (Visalberghi et al., 1998). Previous investigations have shown that social influences increase the acceptance of novel food in different animals such as tufted capuchin monkeys (Visalberghi et al., 1998), and marmosets (Yamamoto and Lopes, 2004; Schrauf et al., 2004).

In our study individual's approaches to novel foods in social contexts indicated that they reduced neophobia. This reduction in neophobia in group might be because they utilized information from conspecifics and then approached novel food in the social context. But their preference to familiar food than novel food was might be due to unusual taste of novel food. Our results are also comparable to Mason and Reidinger (1981) where they showed that red-winged blackbirds (Agelaius phoeniceus) had tendency to utilize the same novel food as conspecifics after observing conspecifics eating that food. According to traditional definition of social facilitation, greater food consumption by focal subjects would only be defined as such if it was temporally synchronized with conspecifics' foraging behavior (Clayton, 1978). The tendency for Eurasian siskin to enhance consumption in the social context (non-feeding conspecifics) should, therefore, be attributed to an elevated motivation to feed rather than an effect of social facilitation. Indeed, rather than facilitating feeding per se, the existence of conspecifics might have decreased focal subjects stress level, increasing food consumption as a corollary. Regardless of actual process involved, our results supported the suggestion that presence of conspecifics exacerbated individual's tendency to reduce neophobia (Fragaszy et al., 2004).

Our study showed that Eurasian siskin dominant males may reduce neophobia in the social context and increase food intake. This was comparable to Dally et al. (2008) showing social context influenced foraging behavior in rooks. However, unlike our results, Fragaszy et al. (2004) found no significant influence of the social context on social facilitation and consumption of novel food in the social context. Since we only used male dominant individuals in the present study, we suggested that sex differences and influence of the social context on personality of Eurasian siskins should need further investigation.

\section{Ethical note}

The experimental procedures were permitted by National Animal Research Authority in Northeast Normal University, China (approval number: NENU-20080416) and the Forestry Bureau of Jilin Province of China (approval number: [2006]178).

\section{ACKNOWLEDGEMENTS}

We thank Zheng Han, Jiangping Yu and Hongwei $\mathrm{Xu}$ for their assistance in this work. We would like to thank two anonymous reviewers for their constructive and helpful comments on our manuscript. This work was supported by the National Natural Science Foundation of China (31470458 to HW), the Fundamental Research Funds for the Central Universities (2412016KJ043) and the Open Project Program of Jilin Provincial Key Laboratory of Animal Resource Conservation and Utilization (130028685). We declare that all authors have no conflict of interest.

\section{Statement of conflict of interest}

Authors have declared no conflict of interest.

\section{REFERENCES}

Addessi, E. and Visalberghi, E., 2006. How social influences affect food neophobia in captive chimpanzees: A comparative approach. In: Cognitive development in chimpanzees (eds. M. Matsuzawa, T., Tomonaga and M. Tanaka), Springer, Tokyo, pp. 246-264. https://doi. org/10.1007/4-431-30248-4_16

Addessi, E., Chiarotti, F., Visalberghi, E. and Anzenberger, G., 2007. Response to novel food and the role of social influences in common marmosets (Callithrix jacchus) and Goeldi's monkeys (Callimico goeldii). Am. J. Primatol., 69: 1-13. https://doi.org/10.1002/ajp.20429

Ahsan, M.M. and Tahir, H.M., 2016. Foraging behaviour of Hottentotta tumulus (Fabricius, 1798) and Odontobuthus odonturus (Pocock, 1897)., 2016. Pakistan J. Zool., 48: 1811-1815.

Beauchamp, G., 1998. The effect of group size on mean food intake rate in birds. Biol. Rev. Camb. Philos., 73: 449-472. https://doi.org/10.1111/j.1469185X.1998.tb00179.x

Bebus, S.E., Small, T.W., Jones, B.C., Elderbrock, E.K. and Schoech, S.J., 2016. Associative learning is inversely related to reversal learning and varies with nestling corticosterone exposure. Anim. Behav., 111: 251-260. https://doi.org/10.1016/j. anbehav.2015.10.027

Brown, C., Jones, F. and Braithwaite, V., 2005. In situ examination of boldness-shyness traits in the tropical poeciliid, Brachyraphis episcopi. Anim. 
Behav., 70: 1003-1009. https://doi.org/10.1016/j. anbehav.2004.12.022

Brown, G.E., Ferrari, M.C.O., Elvidge, C.K., Ramnarine, I. and Chivers, D.P., 2013. Phenotypically plastic neophobia: A response to variable predation risk. Roy. Soc. B-Biol. Sci., 280: 20122712 . http://dx.doi. org/10.1098/rspb.2012.2712

Caraco, T., Martindale, S. and Pulliam, H.R., 1980. Avian flocking in the presence of a predator. Nature, 285: 400-401. https://doi.org/10.1038/285400a0

Clayton, D.A., 1978. Socially facilitated behaviour. Q. Rev. Biol., 53: 373-392. https://doi. org/10.1086/410789

Coppinger, R.P., 1969. The effect of experience and novelty on avian feeding behavior with reference to the evolution of warning colourations in butterflies. Part 1. Reactions of wild caught blue jays to novel insects. Behaviour, 35: 45-60. https://doi. org/10.1163/156853970X00114

Dall, S.R.X., Houston, A.I. and McNamara, J.M., 2004. The behavioural ecology of personality: consistent individual differences from an adaptive perspective. Ecol. Lett., 7: 734-739. https://doi. org/10.1111/j.1461-0248.2004.00618.x

Dally, J.M., Clayton, N.S. and Emery, N.J., 2008. Social influences on foraging by rooks (Corvus frugilegus). Behaviour, 145: 1101-1124. https://doi. org/10.1163/156853908784474470

Drent, P.J., van Oers, K. and van Noordwijk, A.J., 2003. Realized heritability of personalities in the great tit (Parus major). Proc. R. Soc. Lond. B., 270: 45-51. https://doi.org/10.1098/rspb.2002.2168

Drent, R. and Swierstra, P., 1977. Goose flocks and food finding: Field experiments with barnacle geese in winter. Wildfowl, 28: 15-20.

East, M.L. and Hofer, H., 2010. Social environments, social tactics and their fitness consequences in complex mammalian societies. In: Social behaviour: Genes, ecology and evolution (eds T. Szekely, A.J. Moore and J. Komdeur), $1^{\text {st }}$ edn. Cambridge University Press, Cambridge, pp. 360-390. https:// doi.org/10.1017/CBO9780511781360.029

Fragaszy, D.M., Visalberghi, E. and Fedigan, L.M., 2004. The complete capuchin. Cambridge University Press, Cambridge.

Giraldeau, L.A., 2008. Social foraging. In: Behavioural ecology: An evolutionary perspective on behaviour (eds. E. Danchin, L.A. Giraldeau and F. Cezilly). Oxford University Press, Oxford, pp. 257-283.

Goodale, E., Ding, P., Liu, X., Martínez, A., Si, X., Walters, M. and Robinson, S.K., 2015. The structure of mixed-species bird flocks, and their response to anthropogenic disturbance, with special reference to East Asia. Avian Res., 6: 14. https://doi. org/10.1186/s40657-015-0023-0

Greenberg, R. and Mettke-Hofmann, C., 2001. Ecological aspects of neophobia and neophilia in birds. In: Current ornithology (eds. Nolan Jr, Val, Thompson, Charles). Springer, New York, pp. 119178. https://doi.org/10.1007/978-1-4615-1211-0_3

Greenberg, R., 1990. Ecological plasticity, neophobia, and resource use in birds. Stud. Avian. Biol., 13: 431.

Greggor, A.L., Thornton, A. and Clayton, N.S., 2015. Neophobia is not only avoidance: improving neophobia tests by combining cognition and ecology. Curr. Opin. Behav. Sci., 6: 82-89. https:// doi.org/10.1016/j.cobeha.2015.10.007

Heinrich, B., 1988. Why do ravens fear their food? Condor, 90: 950-952. https://doi. org/10.2307/1368859

Herman, C.P., 2015. The social facilitation of eating. A review. Appetite, 86: 61-73. https://doi. org/10.1016/j.appet.2014.09.016

Herman, C.P., Roth, D. and Polivy, J., 2003. Effects of the presence of others on food intake: A normative interpretation. Psychol. Bull., 129: 873-886. https:// doi.org/10.1037/0033-2909.129.6.873

Inglis, I.R. and Isaacson, A.J., 1978. The responses of dark-bellied brent geese to models of geese in various postures. Anim. Behav., 26: 953-958. https://doi.org/10.1016/0003-3472(78)90159-8

Knight, S.K. and Knight, R.L. 1986. Vigilance patterns of bald eagles feeding in groups. Auk, 103: 263272.

Krause, J. and Ruxton, G.D., 2002. Living in groups. Oxford University Press, Oxford.

Laland, K.N., 2004. Social learning strategies. Learn. Behav., 32: 4-14. https://doi.org/10.3758/ BF03196002

Lima, S.L. and Bednekoff, P.A., 1999. Temporal variation in danger drives antipredator behavior: the predation risk allocation hypothesis. Am. Nat., 153: 649-659. https://doi.org/10.1086/303202

Marshall, H.H., Carter, A.J., Marcus Rowcliffe, J. and Cowlishaw, G., 2012. Linking social foraging behaviour with individual time budgets and emergent group-level phenomena. Anim. Behav., 84: 1295-1305. https://doi.org/10.1016/j. anbehav.2012.09.030

Mason, J.R. and Reidinger Jr, R.F., 1981. Effects of social facilitation and observational learning on feeding behaviour of the red-winged blackbird (Agelaius phoeniceus). Auk, 98: 778-784. 
Mateos-González, F. and Senar, J.C., 2012. Melaninbased trait predicts individual exploratory behaviour in siskins, Carduelis spinus. Anim. Behav., 83: 229232. https://doi.org/10.1016/j.anbehav.2011.10.030

Mettke-Hofmann, C., Ebert, C., Schmidt, T., Steiger, S. and Stieb, S., 2005a. Personality traits in resident and migratory warbler species. Behaviour, 142: 1357-1375. https://doi. org/10.1163/156853905774539427

Mettke-Hofmann, C. and Greenberg, R., 2005. Behavioral and cognitive adaptations to longdistance migration. In: Birds of two worlds (eds. R. Greenberg and P.P. Marra). The Johns Hopkins University Press, Baltimore, pp. 114-123.

Palestis, B.G. and Burger, J., 1998. Evidence for social facilitation of preening in the common tern. Anim. Behav., 56: 1107-1111. https://doi.org/10.1006/ anbe. 1998.0907

Pascual, J. and Senar, J.C., 2014. Antipredator behavioural compensation of proactive personality trait in male Eurasian siskins. Anim. Behav., 90: 297 303. https://doi.org/10.1016/j.anbehav.2014.02.002

Pliner, P., Bell, R., Hirsch, E.S. and Kinchala, M., 2006. Meal duration mediates the effect of "social facilitation" on eating in humans. Appetite, 46: 189198. https://doi.org/10.1016/j.appet.2005.12.003

Pulliam, H.R. and Caraco, T., 1984. Living in groups: Is there an optimal group size? In: Behavioural ecology: An evolutionary approach (eds. J.R. Krebs and N.B. Davies), $2^{\text {nd }}$ edn. Blackwell Scientific Publications, Oxford, pp. 122-147.

Sansom, A., Cresswell, W., Minderman, J. and Lind, J., 2008. Vigilance benefits and competition costs in groups: Do individual redshanks gain an overall foraging benefit? Anim. Behav., 75: 1869-1875. https://doi.org/10.1016/j.anbehav.2007.11.005

Schrauf, C., Voelkl, B. and Huber, L., 2004. The response of infant marmosets towards novel food. Folia Primatol., 75: 410-411.

Senar, J.C. and Camerino, M., 1998. Status signaling and the ability to recognize dominants: An experiment with siskin (Carduelis spinus). Proc. $R$. Soc. London B: Biol. Sci., 265: 1515-1520. https:// doi.org/10.1098/rspb.1998.0466

Senar, J.C. and Domenech. J., 2011. Sex-specific aggression and sex ratio in wintering finch flocks: Serins and siskins differ. Acta Ethol., 14: 7-11. https://doi.org/10.1007/s10211-010-0084-3

Senar, J.C., Camerino, M., Copete, J.L. and Metcalfe, N.B., 1993. Variation in black bib of the Eurasian siskin (Carduelis spinus) and its role as a reliable badge of dominance. Auk, 110: 924-927. https:// doi.org/10.2307/4088649

Senar, J.C., Burton, R.J.K. and Metcalfe, N.B., 1992. Variation in the nomadic tendency of a wintering finch Carduelis spinus and its relationship with body condition. Ornis Scand., 23: 63-72. https:// doi.org/10.2307/3676428

Stillman, R.A., Bautista, L.M., Alonso, J.C. and Alonso, J.A., 2002. Modeling state-dependent interference in common cranes. J. Anim. Ecol., 71: 874-882. https://doi.org/10.1046/j.1365-2656.2002.00652.x

Vahl, W.K., Lok, T., Van der Meer, J., Piersma, T. and Weissing, F.J., 2005. Spatial clumping of food and social dominance affect interference competition among ruddy turnstones. Behav. Ecol., 16: 834844. https://doi.org/10.1093/beheco/ari067

Verbeek, M.E.M., Boon, A. and Drent, P.J., 1996. Exploration, aggressive behavior and dominance in pair-wise confrontations of juvenile male great tits. Behavior, 133: 945-963. https://doi. org/10.1163/156853996X00314

Verbeek, M.E.M., Drent, P.J. and Wiepkema P.R., 1994. Consistent individual differences in early exploratory behaviour of male great tits. Anim. Behav., 48: 1113-1121. https://doi.org/10.1006/ anbe.1994.1344

Visalberghi, E. and Addessi, E., 2001. Acceptance of novel foods in capuchin monkeys: do specific social facilitation and visual stimulus enhancement play a role? Anim. Behav., 62: 567-576. https://doi. org/10.1006/anbe.2001.1787

Visalberghi, E. and Fragaszy, D., 1995. The behaviour of capuchin monkeys, Cebus apella, with novel foods: The role of social context. Anim. Behav., 49: 10891095. https://doi.org/10.1006/anbe.1995.0137

Visalberghi, E., Janson, C.H. and Agostini, I., 2003a. Response towards novel foods and novel object in wild tufted capuchins (Cebus apella). Int. J. Primatol., 24: 653-675. https://doi. org/10.1023/A:1023700800113

Visalberghi, E., Myowa-Yamakoshi, M., Hirata, S. and Matsuzawa, T., 2002. Responses to novel foods in captive chimpanzees. Zoo Biol., 21: 539-548. https://doi.org/10.1002/zoo.10057

Visalberghi, E., Valente, M. and Fragaszy, D., 1998. Social context and consumption of unfamiliar foods by capuchin monkeys (Cebus apella) over repeated encounters. Am. J. Primatol., 45: 367-380. https://doi.org/10.1002/(SICI)1098- 
2345(1998)45:4<367::AID-AJP4>3.0.CO;2-U

Voelkl, B., Schrauf, C. and Huber, L., 2006. Social contact influences the response of infant marmosets towards novel food. Anim. Behav., 72: 365-372. https://doi.org/10.1016/j.anbehav.2005.10.013

Wan, W., Zhou, L. and Song, Y., 2016. Shifts in foraging behavior of winter hooded cranes (Grus monacha) in three different habitats at Shengjin Lake, China. Avian Res., 7: 13. https://doi.org/10.1186/s40657016-0047-0

Wilson, D.S., Coleman, K., Clark, A.B. and Biederman, L., 1993. The shy-bold continuum: An ecological study of a psychological trait. J. Comp. Psychol., 107: 250-260. https://doi.org/10.1037/0735-
7036.107.3.250

Yamamoto, M.E. and Lopes, F.A., 2004. Effect of removal from the family group on feeding behavior by captive (Callithrix jacchus). Int. J. Primatol., 25: 489-500. https://doi.org/10.1023/ B:IJOP.0000019164.98756.9c

Yang, L., Zhou, L. and Song, Y., 2015. The effects of food abundance and disturbance on foraging flock patterns of the wintering hooded cranes (Grus monacha). Avian Res., 6: 15. https://doi. org/10.1186/s40657-015-0024-z

Zajonc, R.B., 1965. Social facilitation. Science, 149:269274. https://doi.org/10.1126/science.149.3681.269 